\title{
PERDAS E VALOR NUTRITIVO DA SILAGEM DE CAPIM-TANZÂNIA AMONIZADO COMURÉIA*
}

\author{
LOSSES AND NUTRITIVE VALUE OF UREA AMMONIATED TANZÂNIA GRASS SILAGE
}

\author{
Oliveira, H.C. ${ }^{1}$, A.J.V. Pires ${ }^{1}$, A.C. Oliveira ${ }^{2}$, A.L. Rocha Neto ${ }^{1}$, U. Matos Neto ${ }^{3}$, \\ G.G.P. Carvalho ${ }^{2}$, C.M. Veloso ${ }^{1}$ e U.L.C. Oliveira ${ }^{4}$
}

\begin{abstract}
1'Departamento de Tecnologia Rural e Animal. Universidade Estadual do Sudoeste da Bahia (UESB). Rua Copacabana $n^{0}$ 185. São Francisco. CEP 45700-000 Itapetinga, BA. Brasil. hellenncardoso@bol.com.br ${ }^{2}$ Universidade Federal de Viçosa. Departamento de Zootecnia. Avenida Peter Henry Rolfs, s/n. Campus Universitário Viçosa-MG. CEP 36570-000. Brasil.

${ }^{3}$ Universidade Estadual do Sudoeste da Bahia (UESB). Departamento de Tecnologia Rural e Animal. Praça da Primavera, $\mathrm{n}^{\circ}$ 40. CEP 45700-000. Primavera. Itapetinga-BA. Brasil.

${ }^{4}$ Universidade Estadual do Sudoeste da Bahia (UESB). Estrada do Bem-Querer, km 04. Universitário. CEP 45083-900. Vitória da Conquista-BA. Brasil.
\end{abstract}

\section{PalaVras chaVe adicionais}

Efluente. Digestibilidade in vitro. Panicum maximum.

\section{RESUMO}

Objetivou-se com este experimento avaliar as perdas por efluente e por gases e as alterações na composição bromatológica e na digestibilidade in vitro da matéria seca da silagem de capimTanzânia (Panicum maximum) amonizado. O delineamento experimental utilizado foi o inteiramente casualizado em um esquema fatorial $4 \times 2$, sendo (quatro doses de uréia $0 ; 0,25 ; 0,5$ e $0,75 \%$ base na matéria seca e dois períodos de tratamento 30 e 60 dias), com quatro repetições. As perdas por gases da silagem foram influenciadas, apresentando efeito quadrático negativo $(p<0,05)$ em função das doses de uréia. As perdas por efluente foram maiores no período de 60 dias, não sofrendo efeito das doses de uréia. A amonização nas doses utilizadas não alterou os teores de matéria seca, fibra em detergente neutro, fibra em detergente ácido, nitrogênio insolúvel em detergente neutro, nitrogênio insolúvel em detergente ácido, celulose, hemicelulose e lignina. Os valores de proteína bruta e digestibilidade in vitro da matéria seca aumentaram em função das doses aplicadas.

*Projeto financiado pela UESB.

Recibido: 2-5-07. Aceptado: 5-11-07.

\section{ADDITIONAL KEYWORDS}

Effluent. In vitro dry matter digestibility. Panicum maximum.

\section{SUMMARY}

The aim of this experiment was to evaluate the effluent and gas losses and the alterations of bromatologic composition and in vitro dry matter digestibility of ammoniated Tanzânia grass (Panicum maximum) silage. The experimental design used was the completely randomized in a $4 \times 2$ factorial scheme, being (four urea doses 0.0 , $0.25,0.5$ and $0.75 \%$ dry matter basis and two treatment periods 30 and 60 days), with four repetitions. The silage gases losses were influenced, showing negative quadratic effect $(p<0.05)$ as function of urea doses. The effluent losses were greater in 60 days period, without effect of urea doses. The ammoniation at the doses used did not alter the dry matter, neutral detergent fiber, acid detergent fiber, neutral detergent insoluble nitrogen, acid detergent insoluble nitrogen, celluloses, hemicelluloses and lignin contents. The crude protein and in vitro dry matter digestibility values increased as function of the applied doses.

\section{INTRODUÇÃO}

A utilização de forrageiras tropicais na produção de silagem é um recurso que pode

Arch. Zootec. 58 (222): 195-202. 2009. 
ser utilizado como alternativa de manejo, aproveitando o excedente de forragem produzido no período de maior crescimento, garantindo assim, o fornecimento de volumosos de boa qualidade para os ruminantes. Um dos grandes problemas no processo de ensilagem de forrageiras com alto teor de umidade são as perdas de nutrientes por efluente, e por gases oriundos de fermentação.

Silagens produzidas a partir de forrageiras com baixo teor de matéria seca podem propiciar o desenvolvimento de bactérias do gênero Clostridium, que produzem ácido butírico, provocando a degradação de proteína e ácido lático. A formação de ácido butírico resulta em grandes perdas de matéria seca, em decorrência da produção de $\mathrm{CO}_{2}$ e $\mathrm{H}_{2} \mathrm{O}$ (McDonald, 1981).

Visando amenizar os problemas de fermentação e perdas no processo de ensilagem, alternativas têm sido propostas, como o uso da amonização. As formas mais utilizadas são via uréia $\left(\mathrm{NH}_{2} \mathrm{COONH}_{2}\right)$ ou amônia anidra $\left(\mathrm{NH}_{3}\right)$, com destaque para a uréia pela sua maior disponibilidade, menor custo e facilidade de manuseio.

A amonização de forragens têm sido utilizada com o intuito de conservar forragens com alto teor de umidade, como silagens, e também para a melhoria do valor nutritivo de volumosos em geral por meio do fornecimento de nitrogênio não protéico, pela redução na fração da fibra em detergente neutro (FDN) e pelo aumento na digestibilidade do material tratado (Pires et al., 2003; Carvalho et al., 2006).

A determinação dos teores de nitrogênio, da forma como o mesmo foi incorporado na forragem após o tratamento, é uma das formas de se avaliar a eficiência de utilização de volumosos amonizados. Em estudo realizado com gramíneas tropicais, braquiária decumbens (Brachiaria decumbens) e jaraguá (Hyparrhenia rufa), Reis et al. (2001a) verificaram que aplicação de amônia anidra ou de uréia aumentou os teores de nitrogênio $(\mathrm{N})$ total, $\mathrm{N}$ insolúvel em deter- gente neutro, $\mathrm{N}$ insolúvel em detergente ácido, $\mathrm{N}$ não-protéico e $\mathrm{N}$ amoniacal.

Carvalho et al. (2006) avaliaram a adição de $0 ; 2,5 ; 5$ e $7,5 \%$ de uréia no bagaço de cana-de-açúcar com $40 \%$ de matéria seca (MS) e verificaram elevação nos teores de proteína. Os autores relataram aumentos de 3,$1 ; 6,1$ e 9,2 unidades percentuais, respectivamente, das doses 2,5; 5 e 7,5\% em relação ao tratamento 0\%. Sarmento et al. (1999), ao avaliarem a amonização do bagaço de canade-açúcar contendo $55 \%$ de MS, tratado com doses de $0 ; 2,5 ; 5 ; 7,5$ e $10 \%$ de uréia e $5 \%$ de soja crua moída (base da MS), verificaram acréscimos nos teores de proteína bruta do material tratado de 3,$65 ; 5,59$; 7,$71 ; 9,96$ e $12,54 \%$, respectivamente.

Outro efeito da amonização é sobre a fração fibrosa. Diversos trabalhos mostraram a redução do teor de FDN de materiais amonizados (Reis et al., 2001b; Bertipaglia et al., 2005; Carvalho et al., 2006). Contudo, Rocha et al. (2001), ao estudarem diferentes níveis de uréia $(0,2 ; 4$ e $6 \%)$ no tratamento de silagem de capim-elefante por 60 dias de armazenamento, não verificaram diferenças para os constituintes da parede celular, a não ser para a digestibilidade in vitro da matéria seca (DIVMS), onde os valores encontrados foram de 41,90; 52,30; 56,01 e $55,02 \%$, respectivamente, para as doses citadas, mostrando o efeito da amonização na melhoria do valor nutritivo da silagem.

A falta de resposta da amonização sobre os teores da fração fibrosa pode estar associado a fatores como dose aplicada, fonte de nitrogênio, material tratado, período de tratamento e teor de umidade, uma vez que, estes fatores podem influenciar o resultado da amonização (Pires et al., 2003).

Objetivou-se com este experimento avaliar o efeito de diferentes doses de uréia, em combinação com dois períodos de tratamento, sobre as perdas por efluente e por gases e as alterações na composição bromatológica e na digestibilidade in vitro da matéria seca da silagem de capimTanzânia. 


\section{MATERIALEMÉTODOS}

O experimento foi desenvolvido no laboratório de Forragicultura e Pastagens, da Universidade Estadual do Sudoeste da Bahia, UESB, no Campus Juvino Oliveira, na cidade de Itapetinga, BA, de maio a setembro de 2005.

O delineamento experimental utilizado foi o inteiramente casualizado em um esquema fatorial $4 \times 2$, sendo quatro doses de uréia: $0 ; 0,25 ; 0,5$ e $0,75 \%$ com base na matéria seca, a aplicação da mesma foi feita no momento da ensilagem, dispensando a diluição em água, já que a gramínea possuía umidade suficiente para favorecer a amonização e dois períodos de tratamento, 30 e 60 dias, com quatro repetições, totalizando 32 unidades amostrais.

Foi utilizado para ensilagem o capimTanzânia (Panicum maximum). Antes da adição de uréia foram coletadas amostras do capim para analise de sua composição químico- bramatológica (tabela I). A gramínea foi picada, homogeneizada, pesada e ensilada em silos experimentais de PVC com $50 \mathrm{~cm}$ de comprimento por 10 de diâmetro, contendo válvula de Bulsen, tela e areia no fundo, que foram anteriormente pesados para a obtenção das perdas por efluente no momento da abertura dos silos. O material

Tabela I. Composição bromatológica $(\% \mathrm{da}$ $M S)$ e digestibilidade in vitro da matéria seca do capim-Tanzânia. (Bromatologic composition (DM basis) and in vitro dry matter digestibility of the Tanzânia grass).

\begin{tabular}{lc}
\hline Item & $\begin{array}{c}\text { Composição } \\
\text { (\% da MS) }\end{array}$ \\
\hline Matéria seca & 23,7 \\
Proteína bruta & 6,4 \\
Fibra em detergente neutro & 79,9 \\
Fibra em detergente ácido & 55,4 \\
Hemicelulose & 24,2 \\
Celulose & 43,3 \\
Lignina & 6,4 \\
Digestibilidade in vitro da matéria seca & 48,6 \\
\hline
\end{tabular}

foi ensilado usando uma compactação de $600 \mathrm{~kg}$ de capim verde por metro cúbico, e posteriormente os silos foram vedados e pesados.

Ao término de cada período de tratamento (30 e 60 dias), os silos foram novamente pesados para se obter as perdas por gases e por efluentes sendo calculado por diferença de peso. As perdas por gases foram estimadas pela divisão dos gases quantificados pela forragem ( $\mathrm{kg}$ de MS) e as perdas por efluentes foram obtidas pela quantificação dos pesos dos silos com a areia antes da ensilagem e após a abertura dos silos (peso/peso). Após abertura o material permaneceu em aeração por 04 horas para eliminação do excesso de amônia, em seguidas as amostras foram homogeneizadas e coletadas.

As amostras foram pré-secas em estufa de circulação forçada de ar em temperatura de $55^{\circ} \mathrm{C}$ por 72 horas, para minimizar perdas de nitrogênio por volatilização, sendo em seguida as amostras moídas em peneira de $1 \mathrm{~mm}$, em moinho de Willey e submetido a análises para estimação dos teores de nitrogênio total (NT), fibra em detergente neutro (FDN), fibra em detergente ácido (FDA), hemicelulose, celulose, lignina, nitrogênio insolúvel em detergente neutro (NIDN), nitrogênio insolúvel em detergente ácido (NIDA) e digestibilidade in vitro da matéria seca (DIVMS). Todos estes procedimentos seguiram as metodologias descritas em Silva e Queiroz (2002).

Os resultados obtidos das análises dos dados de perdas de matéria seca por gases e efluente das silagens foram analisados por meio de análise de variância e de regressão adotando-se o nível de probabilidade de $5 \%$.

As análises estatísticas foram realizadas segundo Ribeiro Júnior (2001).

\section{RESULTADOSEDISCUSSÃO}

As perdas por gases da silagem foram influenciadas de forma quadrática negativa 
$(\mathrm{p}<0,05)$ pelas doses de uréia. Estimou-se o valor mínimo de $1,27 \%$ de perdas para a dose de $0,58 \%$ de uréia, com 30 dias de amonização, e de $4,18 \%$ de perdas para o período de 60 dias. Essa diferença ocorreu em função do maior período de fermentação, e conseqüentemente, propiciou maiores perdas por gases, demonstrando que mesmo em doses baixas o uso da uréia foi eficiente na conservação do material tratado (tabela II).

Souza et al. (2005), trabalhando com silagens de cana-de-açúcar utilizando inoculantes químicos e bacterianos, observaram que a uréia e o aditivo contendo bactérias homo e heterofermentativas diminuíram as perdas por gases em relação ao controle (28,01 e $22,18 \%$ contra $32,50 \%$ do controle), respectivamente.

As perdas de MS podem estar principalmente relacionadas com o aumento da produção de gás, promovido através da fermentação por microorganismos produtores de $\mathrm{CO}_{2}$. De acordo com McDonald et al. (1991), na fermentação por bactérias do gênero Clostrodium onde ocorrem descarboxilização e ou oxidação há altas perdas por gases $\left(\mathrm{CO}_{2}\right)$.

Neiva et al. (1998) estudaram o efeito da amonização na dose de $1,2 \%$ de amônia anidra sobre a fermentação de silagens de milho e constataram que as silagens amonizadas apresentavam sempre uma me-

Tabela II. Percentual de matéria seca (MS), proteína bruta (PB), nitrogênio insolúvel em detergente neutro (NIDN/NT), nitrogênio insolúvel em detergente ácido (NIDA/NT), fibra em detergente neutro (FDN), fibra em detergente ácido (FDA), celulose, hemicelulose, lignina e digestibilidade in vitro da matéria seca (DIVMS) de silagens de capim-Tanzânia amonizado com doses crescentes de uréia em diferentes períodos. (Percentage of dry matter (MS), crude protein (PB), neutral detergent insoluble nitrogen (NIDN/NT), acid detergent insoluble nitrogen (NIDA/NT), neutral detergent fiber (FDN) and acid detergent fiber (FDA), celluloses, hemicelluloses, lignin and in vitro dry matter digestibility of silages of tanzânia grass ammoniated with increasing doses of urea in different periods).

\begin{tabular}{|c|c|c|c|c|c|c|c|c|c|c|c|}
\hline \multirow[t]{3}{*}{ Parâmetro } & \multicolumn{8}{|c|}{ Tratamentos } & \multirow{2}{*}{\multicolumn{3}{|c|}{ Valor de $p$}} \\
\hline & \multicolumn{4}{|c|}{$\mathrm{D}=30$ dias } & \multicolumn{4}{|c|}{$\mathrm{D}=60$ dias } & & & \\
\hline & 0 & 0,25 & 0,50 & 0,75 & 0 & 0,25 & 0,50 & 0,75 & U & $\mathrm{P}$ & UxP \\
\hline MS & 24,3 & 22,7 & 23,5 & 23,2 & 24,1 & 23,9 & 23,1 & 23,1 & NS & NS & NS \\
\hline $\mathrm{PB}^{1}$ & 6,6 & 6,9 & 6,9 & 7,7 & 5,0 & 6,2 & 8,0 & 8,0 & 0,0021 & NS & NS \\
\hline NIDN & 27,1 & 26,3 & 30,6 & 27,0 & 31,0 & 24,5 & 24,3 & 20,4 & NS & NS & NS \\
\hline NIDA & 26,5 & 23,7 & 25,2 & 23,3 & 23,6 & 18,5 & 15,9 & 20,4 & NS & NS & NS \\
\hline FDN & 79,7 & 79,9 & 79,7 & 79,6 & 79,5 & 79,9 & 80,6 & 80,0 & NS & NS & NS \\
\hline FDA & 51,8 & 54,8 & 53,9 & 57,5 & 55,4 & 54,3 & 58,4 & 58,4 & NS & NS & NS \\
\hline Celulose & 41,3 & 43,4 & 42,2 & 46,4 & 44,1 & 44,9 & 46,3 & 45,4 & NS & NS & NS \\
\hline Hemicelulose & 27,8 & 25,1 & 25,8 & 22,1 & 24,1 & 25,6 & 22,2 & 21,6 & NS & NS & NS \\
\hline Lignina & 5,4 & 6,1 & 5,7 & 6,1 & 5,7 & 6,8 & 6,6 & 6,3 & NS & NS & NS \\
\hline DIVMS $^{2}$ & 41,4 & 45,3 & 46,4 & 50,3 & 41,9 & 45,6 & 45,9 & 54,9 & 0,0005 & NS & NS \\
\hline Perda por gases ${ }^{3}$ & ${ }^{3} 6,1$ & 1,6 & 2,5 & 1,2 & 7,5 & 4,5 & 5,1 & 4,0 & 0,0000 & 0,0000 & 0,0002 \\
\hline
\end{tabular}

$U=$ doses de uréia; $D=$ duração do tratamento. NS: $p>0,05$, teste $F$; ${ }^{*} p<0,05$, teste $F$; ${ }^{* *} p<0,01$, teste $F$. Equações de regressão:

${ }^{1} Y=5,8502+2,83811^{* *} x$ Uréia, $r^{2}=70,9$.

${ }^{2} Y=41,4276+13,4015^{* *} \times$ Uréia, $r^{2}=68,6 \%$.

${ }^{3} \mathrm{P}=30: Y=5,74344-15,3128^{* *} \times U+13,1121^{* *} U^{2}, r^{2}=77,4 ; P=60: Y=7,25195-9,64755^{* *} \times U+7,58171^{*}$ $\mathrm{U}^{2}, \mathrm{r}^{2}=77,1$.

Archivos de zootecnia vol. 58, núm. 222, p. 198. 
nor concentração de ácido butírico. O que pode ter ocorrido com o uso da uréia no presente trabalho, causando a inibição deste tipo de fermentação e reduzindo perdas por gases.

Verificou-se efeito $(p<0,05)$ para interação dose de uréia e período de tratamento apresentando maiores perdas por gases no período de 60 dias (tabela II), demonstrando uma maior eficiência da uréia na redução de perdas por gases aos 30 dias. Estes resultados corroboram os encontrados por Roth et al. (2005) que, trabalhando com silagens de capim-Marandú observaram no período de 15 dias uma produção de gás relativamente baixa, no entanto com 60 dias observaram um aumento de 4,3 pontos percentuais nas perdas.

Para a variável perdas por efluente não foi verificado efeito $(p>0,05)$ da interação de doses de uréia e período de tratamento, porém, foi verificado efeito $(\mathrm{p}<0,05)$ para período de tratamento. O maior tempo de armazenamento propiciou maior produção de efluente (figura 1), enquanto as doses de uréia adicionadas não provocaram alterações para essa variável, por serem muito baixas para provocar o aumento no teor de matéria seca. Roth et al. (2005), ao avaliarem o capim-Marandú, nos períodos de $1,5,15$ e 60 dias de armazenamento, observaram que até o $15^{\circ}$ dia houve aumento na produção de efluente, permanecendo estável nos demais períodos. Conforme os autores, no período inicial de fermentação, as reações bioquímicas ocorrem com maior intensidade, produzindo água metabólica e há percolação desta pela massa ensilada gerando aumento na produção de efluente.

Não foi verificado efeito $(p>0,05)$ da dose

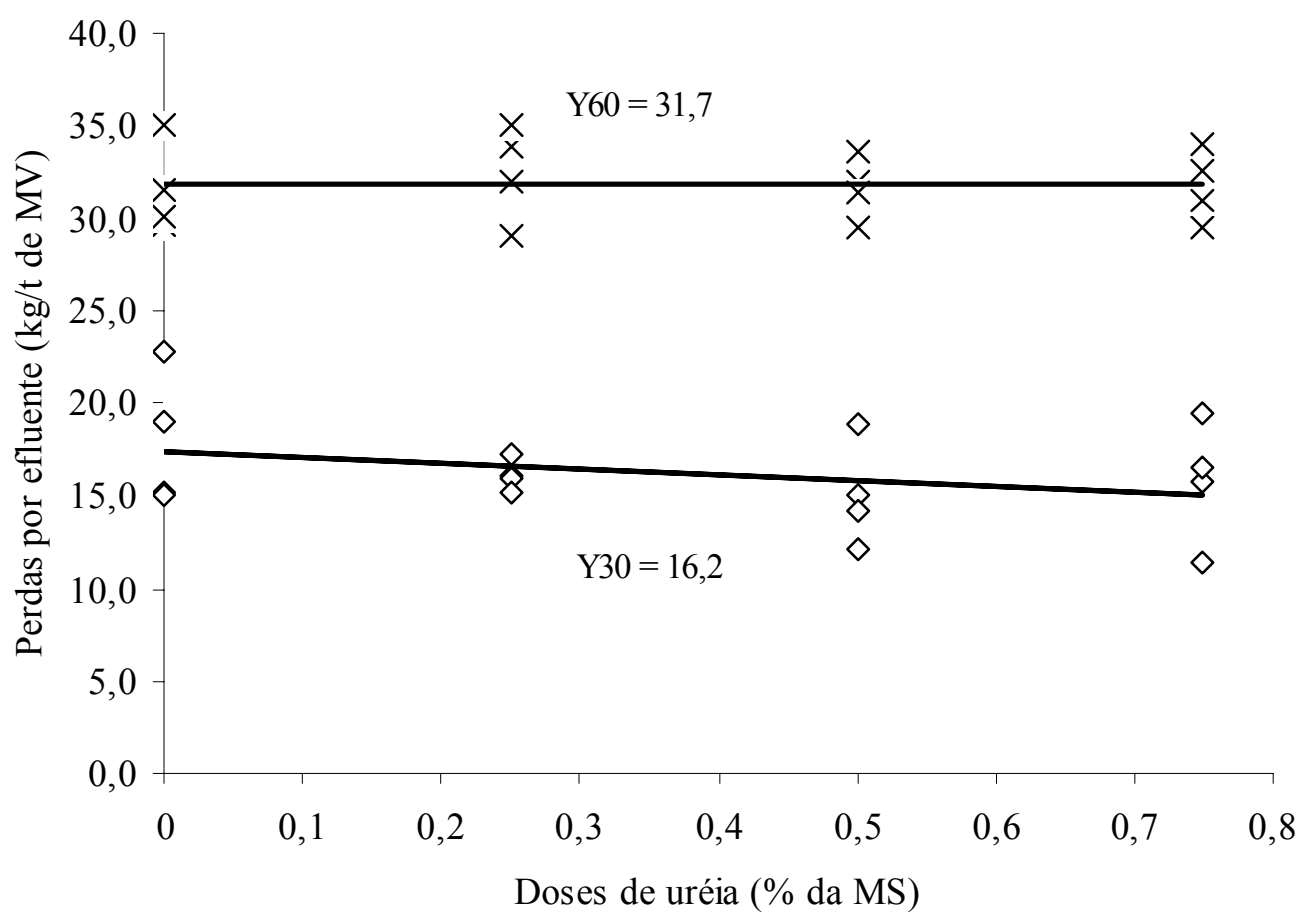

Figura 1. Perdas por efluente ( $\mathrm{kg} / \mathrm{t}$ de material verde) de silagens de capim-Tanzânia amonizado com doses crescentes de uréia em diferentes períodos. (Losses for effluent $(\mathrm{kg} / \mathrm{t}$ of green material) of silages of Tanzânia grass ammoniated with increasing doses of urea in different periods). 
de uréia nem do período de tratamento para as variáveis MS, NIDN/NT e NIDA/NT, enquanto para a $\mathrm{PB}$ os valores aumentaram linearmente em função da amonização (tabela II) sendo atribuído um aumento de 2,84\% de PB para cada unidade de uréia adicionada. Estes incrementos estão relacionados ao fato da uréia fornecer nitrogênio não protéico mesmo quando utilizadas em doses baixas.

Schmidt et al. (2003) verificaram após tratamento do feno de braquiária com $5 \%$ de uréia, que a amonização elevou os teores de PB em $259 \%$. Conforme os autores, essa alteração esta ligada à retenção de nitrogênio, e esta, à atividade ureolítica responsável pela transformação da uréia em amônia. Reis et al. (2001b) observaram, após o tratamento de feno de Brachiaria decumbens com uréia (5,4\% da MS), aumento de $193 \%$ no teor de PB. De forma semelhante o presente trabalho também foi verificado aumento no teor de PB de 12,1; 29,3 e 34,5\% em relação ao controle. Esses incrementos foram menos expressivos devido às doses utilizadas terem sido baixas.

Resultados semelhantes ao presente estudo foram observados por Fernandes et al. (2002) que avaliaram o feno de Brachiaria decumbens submetido ao tratamento com amônia anidra ( $3 \% \mathrm{NH}_{3}$ na $\left.\mathrm{MS}\right)$ e uréia ( $5 \%$ na MS) e não verificaram alterações nos teores de NIDN e NIDA. Entretanto, Gobbi et al. (2005), trabalhando com feno de Brachiaria decumbens tratado com uréia nas doses de $0 ; 2 ; 4 ; 6$ e 10\% (base na MS), observaram redução dos teores de NIDN e NIDA (\% do $\mathrm{N}$ total), em função dos níveis crescentes de uréia.

Não se observou efeito $(\mathrm{p}>0,05)$ de doses de uréia nem de período de tratamento para as frações FDN, FDA, hemicelulose, celulose e lignina (tabela II). O comportamento verificado pode ser explicado em função das doses utilizadas terem sido baixas, objetivando a redução dos custos na produção de silagem, não sendo assim suficiente para solubilizar parte dos componentes da parede celular do material tratado.
Trabalhos de pesquisa têm mostrado que o efeito da amonização sobre os teores de FDA, celulose e lignina não têm sido consistentes, sendo observadas reduções, ausência de efeito ou elevações nos seus teores (Fernandes et al., 2002; Reis et al., 2001b, 2001c; Schmidt et al., 2003), porém, na maioria das pesquisas estas variáveis têm permanecido constantes.

É importante considerar que as respostas à amonização de volumosos variam em função de diversos fatores, como conteúdo de umidade do material tratado e características químicas da planta (Van Soest, 1994).

Para a DIVMS observou-se efeito linear crescente $(p<0,05)$ em função das doses de uréia utilizadas (tabela II). O aumento médio em unidades percentuais da DIVMS foi de 3,$9 ; 5,0 ;$ e 8,9 aos 30 dias e de 3,$7 ; 4,0$ e 13,0 aos 60 dias, respectivamente, para as doses de 0,$25 ; 0,5$ e $0,75 \%$ de uréia em relação ao tratamento $0 \%$.

De acordo com Pires et al. (2004), a amonização de volumosos proporciona a solubilização parcial da hemicelulose e afrouxamento da parede celular, permitindo, dessa forma, que os microrganismos do rúmen tenham maior superfície específica para se agregarem e, consequentemente, aumentarem a digestibilidade.

No presente trabalho a amonização revelou o seu potencial sobre a fração fibrosa, que mesmo sem alterar os constituintes da parede celular, atuou expandindo a mesma, facilitando o ataque dos microrganismos e refletindo positivamente na digestibilidade. O aumento da DIVMS foi de 13,4 unidades percentuais para cada unidade na dose de uréia.

De forma semelhante Fernandes et al. (2002) trabalhando com feno de Brachiaria decumbens submetido ao tratamento com amônia anidra $\left(3 \% \mathrm{NH}_{3}\right.$ na MS) ou uréia $(5 \%$ na MS) observaram aumentos da DIVMS dos fenos em 12,06 e 6,64 unidades percentuais, respectivamente, quando comparados ao controle. Reis et al. (1991) trabalhando com fenos de capim Braquiária 


\section{SILAGEM DE CAPIM-TANZÂNIAAMONIZADO COMURÉIA}

e gordura, tratados com $0,2,4$ e $6 \%$ de amônia anidra também verificaram elevação na DIVMS. Os valores encontrados foram: 16,$55 ; 23,80 ; 28,50$ e 10,$80 ; 17,97 ; 24,69$ unidades percentuais, respectivamente, para as doses estudadas.

\section{CONCLUSÕES}

A amonização do capim-Tanzânia utili-

\section{BIBLIOGRAFIA}

Bertipaglia, L.M.A., S. Luca, G.M.P. Melo e R.A. Reis. 2005. Avaliação de fontes de urease na amonização de fenos de Brachiaria brizantha com dois teores de umidade. Rev. Bras. Zootecn., 34: 378-386.

Carvalho, G.G.P., A.J.V. Pires, C.M. Veloso, A.F. Magalhães, M.A.L. Freire, F.F. Silva, R.R. Silva e B.M.A. Carvalho. 2006. Valor nutritivo do bagaço de cana-de-açúcar amonizado com quatro doses de uréia. Pesqui. Agropecu. Bras., 41: 125-132.

Fernandes, L.O., R.A. Reis, L.R.A. Rodrigues, I.L. Ledic e R.J. Manzan. 2002. Qualidade do feno de Brachiaria decumbens Stapf. submetido ao tratamento com amônia anidra ou uréia. Rev. Bras. Zootecn., 31: 1325-1332.

Gobbi, K.F., R. Garcia, A.F. Garcez Neto, O.G. Pereira, F.S. Bernardino e F.C. Rocha. 2005 Composição química e digestibilidade in vitro do feno de Brachiaria decumbens Stapf. tratado com uréia. Rev. Bras. Zootecn., 34: 720-725.

McDonald, P. 1981. The biochemistry of silage. John Wiley \& Sons. New York. 207 p.

McDonald, P., A.R. Henderson and S.J.E. Heron. 1991. The biochemistry of silage. 2 ed. Chalcomb Publications. Marlow. 340 p.

Neiva, J.N.M., R. Garcia, S.C. Valadares Filho, F.C Silva, A.J.V. Pires e O.G. Pereira. 1998. Características fermentativas das silagens de milho amonizadas. Rev. Bras. Zootecn., 27: 474-480.

Pires, A.J.V., R. Garcia, A.L. Souza, F.F. Silva, C.M. Veloso, G.C. Cardoso, T.N. Oliveira e P.A Silva. 2003. Avaliação do consumo de silagens de sorgo tratadas com amônia anidra, e, ou, sulfeto de sódio na alimentação de novilhas $3 / 4$ Indubrazil/Holandês. Rev. Bras. Zootecn., 32: 1525-1531. zando uréia mostra-se uma prática eficiente na redução de perdas por gases, não demonstrando o mesmo efeito para perdas por efluente nas doses estudadas, com maior intensidade de perdas ocorrendo no período de 60 dias comparado aos 30 dias.

As doses de uréia adicionadas na ensilagem de capim-Tanzânia aumentam os teores de proteína bruta e a digestibilidade in vitro da matéria seca das silagens.

Pires, A.J.V., R. Garcia, S.C. Valadares Filho, O.G. Pereira, P.R. Cecon, F.F. Silva, P.A. Silva e L.C.V. Itavo. 2004. Degradabilidade do bagaço de cana-de-açúcar tratado com amônia anidra e, ou, sulfeto de sódio. Rev. Bras. Zootecn., 33: 1071-1077.

Reis, R.A., R. Garcia, A.C. Queiroz, D.J. Silva e J.Q. Ferreira. 1991. Efeitos da amonização sobre a qualidade do feno de gramíneas tropicais. Pesqui. Agropecu. Bras., 26: 1183-1191.

Reis, R.A., L.R.A. Rodrigues, K.T. Resende, J.R.A. Pereira e A.C. Ruggieri. 2001a. Avaliação de fontes de amônia para o tratamento de fenos de gramíneas tropicais. II. Compostos nitrogenados. Rev. Bras. Zootecn., 30: 682-686.

Reis, R.A., L.R.A. Rodrigues, J.R.A. Pereira e A.C. Ruggieri. 2001b. Composição química e digestibilidade de fenos tratados com amônia anídra ou uréia. Rev. Bras. Zootecn., 30: 666673.

Reis, R.A., L.R.A. Rodrigues, K.T. Resende, J.R.A. Pereira e A.C. Ruggieri. 2001c. Avaliação de fontes de amônia para o tratamento de fenos de gramíneas tropicais. I. Constituintes da parede celular, poder tampão e atividade ureática. Rev. Bras. Zootecn., 30: 674-681.

Ribeiro Júnior, J. 2001. Análises Estatísticas no SAEG, Sistema de análises estatísticas e genéticas. Versão 8.1. UFV. Viçosa. 301 p.

Rocha, F.C., R. Garcia, O.G.P. Pereira, A.W.P. Freitas e F.S. Bernardino. 2001. Níveis de uréia e períodos de amonização sobre o valor nutritivo da silagem de capim-elefante (Pennisetum purpureum Schum)- cv. Napier. Em: Reunião Anual da Sociedade Brasileira de Zootecnia, 38. 2001. Piracicaba. Anais. Sociedade Brasileira de Zootecnia. Piracicaba. p. 373-375. 


\section{OLIVEIRAETAL.}

Roth, A.P.T.P., T.F. Bernardes, R.A. Reis, G.R. Siqueira, R.C. Amaral, R.R. Monteiro, B. Cantarelli e M.T.P. Roth. 2005. Perdas durante a fermentação de silagens de capim-Marandu (Brachiaria brizantha cv. Marandu) tratadas com aditivos químicos e inoculantes bacterianos. Em: Reunião Anual da Sociedade Brasileira de Zootecnia, 42. 2005. Goiânia, Goiás. Anais. Reunião Anual da Sociedade Brasileira de Zootecnia. Goiânia. Goiás.

Sarmento, P., R. Garcia, A.J.V. Pires e A. Nascimento. 1999. Tratamento do bagaço de cana-de-açúcar com uréia. Rev. Bras. Zootecn., 28: 1203-1208.

Schmidt, P., F.S. Wechsler, F.M. Vargas Júnior e P. Rossi. 2003. Valor nutritivo do feno de braquiária amonizado com uréia ou inoculado com Pleurotus ostreatus. Rev. Bras. Zootecn.,
32 (Suplemento, 2): 2040-2049.

Silva, D.J. eA.C. Queiroz. 2002. Análise de alimentos: métodos químicos e biológicos. UFV. Viçosa. $235 \mathrm{p}$.

Souza, D.P., W.R.S. Mattos, L.G. Nussio, L.J. Mari, M.C. Santos, M. Zopollatto, P. Shimdt, J.L. Ribeiro, O.C.M. Queiroz, M.C. Junqueira, M.S. Camargo, S.G. Toledo Filho e R.N. Figueiró. 2005. Avaliação das perdas por efluente em gases em silagens de cana- de- açúcar aditivadas com inoculantes químicos e bacterianos. Em: Reunião Anual da Sociedade Brasileira de Zootecnia, 42. 2005. Goiânia, Goiás. Anais. Reunião Anual da Sociedade Brasileira de Zootecnia. Goiânia, Goiás.

Van Soest, P.J. 1994. Nutritional ecology of the ruminant. 2 ed. Cornell University Press. Ithaca. $476 \mathrm{p}$.

Archivos de zootecnia vol. 58, núm. 222, p. 202. 